\title{
REVISÃo SOBRE USO DE SÍLICA NOS PNEUS AUTOMOTIVOS PARA REDUÇÃO DE CONSUMO DE COMBUSTÍVEL
}

\author{
Rosiana da Silva Lopes ${ }^{1}$, Paulo César S. de Araújo ${ }^{2}$, Sandro Marcos Campos Soares ${ }^{2}$ e \\ Fabrício José Pacheco Pujatti ${ }^{1}$ \\ ${ }^{1}$ Universidade Federal de Minas Gerais - UFMG - Departamento de Engenharia Mecânica \\ ${ }^{2}$ Fiat Chrysler Automobiles - FCA Latam \\ E-mails: rosianalopes16@gmail.com, paulo.araujo@ fcagroup.com, \\ sandro.soares@fcagroup.com e pujatti@demec.ufmg.br
}

\section{RESUMO}

Este artigo apresenta uma revisão o uso de sílica nos pneus automotivos para redução de consumo de combustível. A indústria automotiva está sendo continuamente incentivada a desenvolver veículos mais eficientes em termos de consumo de combustível e emissões de poluentes. Uma forma de aumentar a eficiência dos veículos é reduzir a resistência total ao deslocamento do veículo que inclui a resistência ao rolamento dos pneus, que é responsável por aumentar em até $30 \%$ o consumo de combustível do veículo. Para reduzir o consumo de combustível os fabricantes de pneumáticos desenvolveram pneus de baixa resistência ao rolamento (às vezes chamados de "pneu verde"), que conservam as características de desempenho dos pneus, por meio da combinação de matéria primas diversas e construção do pneu. Este artigo objetiva revisar a literatura sobre a inserção da sílica na composição da borracha de pneus automotivos para reduzir consumo de combustível por meio da redução da resistência ao rolamento. Com a discussão conclui-se que o desenvolvimento de pneus com melhores propriedades de resistência ao rolamento é complexo, pois envolve a combinação de diferentes propriedades como dirigibilidade, capacidade de frenagem, conforto, consumo, entre outros e que a adição de sílica na borracha para fabricação de pneus é um importante avanço tecnológico no desenvolvimento de pneus mais eficientes, pois o seu uso associado a um trabalho de combinação com os demais componentes propiciam pneus com baixa resistência ao rolamento e com as demais propriedades interessantes para aplicação em veículos corroborando para produção de veículos mais econômicos.

\section{INTRODUÇÃO}

O consumo de energia dos veículos automotivos impacta na exploração de energia fóssil extraída do petróleo, que é uma fonte de energia finita. Uma vez que seu uso e extração provocam impactos ambientais de grande magnitude à sociedade e as autoridades de vários países têm cobrado da indústria automotiva veículos mais eficientes, que ao mesmo tempo diminuam o uso de combustíveis fósseis e as emissões de poluentes, aliado ao alto desempenho e preço competitivo [1].

Um veículo automotivo é composto por vários sistemas, o principal deles é o Powertrain (trem de força) constituído basicamente pelo motor, caixa de transmissão, diferencial, eixos, 
rodas e pneus. O Powertrain é responsável pela função básica do veículo, fornecer potência para deslocar o veículo. A força trativa necessária para acelerar o veículo tem origem na combustão da mistura ar-combustível no motor, que converte energia química em térmica e depois em mecânica. A energia mecânica é transmitida as rodas e pneus, onde surge a força trativa na presença de aderência do pneu com a pista. Portanto os pneus são componentes fundamentais para o desempenho do veículo, pois é por meio deles que ocorre a interação entre o veículo e a pista [1], [2] e [3].

Contudo os pneus dissipam parte da energia do combustível devido à força de resistência ao rolamento que surge em decorrência das propriedades viscoelásticas da borracha, que é o principal constituinte dos pneus automotivos. Com a atual preocupação devido o elevado consumo de energia fóssil mundial o setor automotivo promoveu o desenvolvimento tecnológico na produção de pneus mais eficientes para reduzir o consumo de combustível dos veículos automotivos [4] e [5].

Nesse contexto surgiram os pneus de baixa resistência ao rolamento que possuem uma composição diferenciada, com adição de dióxido de silício (sílica), com o objetivo de reduzir o consumo de energia dissipada pela resistência ao rolamento, contudo, sem perder características de segurança, relacionadas à frenagem e durabilidade [1].

Este artigo tem o objetivo de revisar a literatura sobre o uso de sílica na composição da borracha dos pneus automotivos para redução de consumo de combustível.

\section{REVISÃO DA LITERATURA}

\subsection{Funções dos pneumáticos}

Os pneus desempenham função essencial em um veículo automotivo, pois eles fornecem aderência necessária para que a força trativa seja transmitida à pista. Eles precisam ser resistentes às cargas verticais, cargas de flexão lateral, impactos e perfuração.

O projeto de um pneu envolve a obtenção de várias propriedades, relacionadas ao desempenho dos veículos, dirigibilidade tanto em pista seca como molhada, distância de frenagem, problemas de aquaplanagem, consumo de combustível, conforto, resistência ao desgaste, impactos e perfurações, entre outros aspectos que um projeto deve equilibrar de acordo com a aplicação do pneu para obter um produto de qualidade [1].

Em funcionamento os pneus são deformados ciclicamente, como a borracha que os constitui é um material viscoelástico, parte da energia usada na sua deformação é dissipada em forma de calor devido à histerese. Essa perda de energia é conhecida como resistência ao rolamento, que juntamente com a resistência aerodinâmica são as maiores responsáveis pela força de resistência total ao deslocamento do veículo e quanto maior a resistência ao deslocamento maior deve ser o consumo de combustível do veículo [6] e [7]. 


\subsection{Resistência ao rolamento}

A resistência ao rolamento é definida como a energia dissipada ou consumida por distância percorrida, originada pela histerese da borracha. Essa força depende de vários parâmetros operacionais como pressão interna, velocidade, carga vertical aplicada, temperatura da via, tipo da pista e também de parâmetros construtivos dos pneus como o tipo de carcaça, composição da borracha, peso do pneu, etc. [1] e [4].

A histerese é a defasagem entre a retirada da força ou carga aplicada e o retorno do material deformado a sua forma original. Na prática os pneus não recuperam a sua forma antes do próximo ciclo de deformação iniciar, resultando em absorção de energia em forma de calor pela sua estrutura, perdendo potência líquida do motor que seria transmitida a via para gerar deslocamento, consequentemente esse comportamento reduz a eficiência energética do veículo, aumentando o consumo de combustível e de emissões de poluentes. Como a histerese provoca aumento de temperatura interna da borracha, ocorre o aceleramento das reações químicas que contribuem para o envelhecimento do pneu [1] e [6].

A resistência ao rolamento tem sido uma preocupação da industria automotiva há muito tempo, mas inicialmente o objetivo estava focado em melhorar o desempenho dos veículos. Hoje em dia, contudo, as autoridades de vários países tem se voltado às questões ambientais, a preservação do meio ambiente e dos recursos naturais finitos como as fontes de energia fóssil. Pelo fato dos pneus serem responsáveis por boa parte do consumo de combustível automotivo, que utiliza combustível fóssil em sua maioria, há necessidade de continuar um processo de desenvolvimento de pneus cada vez mais eficiêntes [1].

As perdas devido à resistência ao rolamento podem chegar a $30 \%$ do combustível consumido pelo motor. Esse valor justifica o desenvolvimento de pneus com melhores propriedades com relação ao consumo de combustível, atualmente já se encontra em utilização pneus bem mais eficientes que algumas décadas atrás, eles são conhecidos como pneus de baixa resistência ao rolamento inicialmente popularizado como "pneus verdes" pelo fato serem mais econômicos [1] e [8].

\subsection{Composição dos pneus}

A Figura 1 apresenta os principais componentes de um pneu automotivo do tipo radial sem câmara de ar.

Cada parte dos pneus tem importantes funções. A banda de rodagem, que é constituída basicamente de borracha é a parte que efetivamente entra em contato com o solo, sendo responsável pela transmissão de força trativa, pela segurança do veículos. Na banda de rodagem geralmente estão presentes sulcos com a função de drenar a água e evitar perda de aderência do pneu em pista molhada, os sulcos também ajudam a aumentar a aderência com o solo em pista seca, e podem ter diferentes configurações de acordo com a aplicação do pneu [1].

A carcaça é composta de tecidos metálicos ou de nylon emborrachados, sendo responsável pela resistência estrutural, ela pode ser do tipo radial ou diagonal, de 
acordo com a forma com que os fios dos tecidos são dispostos em relação ao talão, nos pneus radiais os fios são posicionados perpendiculares ao talão e paralelos entre si, nos diagonais os fios são cruzados entre si e formam ângulos entre $25^{\circ}$ e $40^{\circ} \mathrm{com}$ o talão. Os pneus radiais geralmente apresentam menor resistência ao rolamento por conta das suas caraterísticas de deformação [4].

Figura 1: Estrutura de um pneu radial tubeless. Adaptado [4].

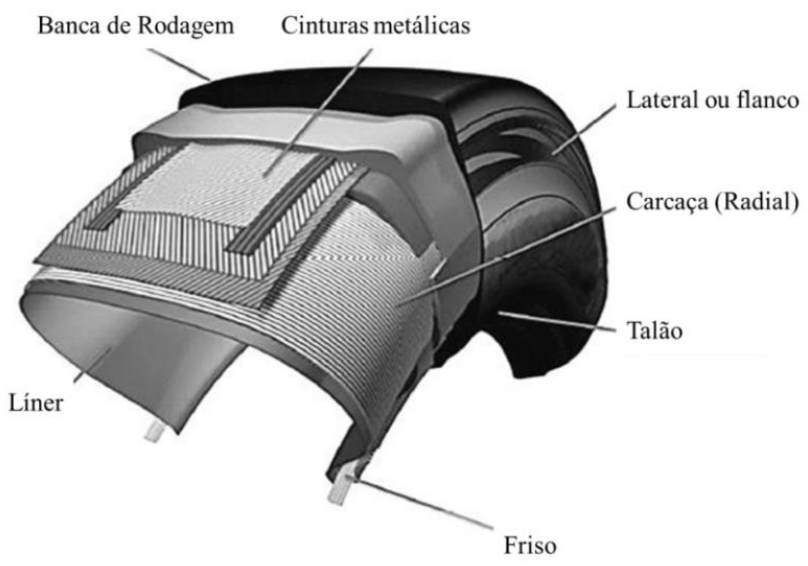

As cintas estabilizadoras são tecidos emborrachados colocados nos pneus radiais para melhorar sua resistência estrutural e manter a forma do pneu quando inflado. A lateral ou flanco é a parte lateral do pneu, que deve ser resistente à flexão e a perfurações. O liner é uma camada de borracha interna colocada nos pneus sem câmara. $\mathrm{O}$ talão é a parte do pneu fixada na roda e o friso é um conjunto de fios metálicos colocado no interior do talão para ancorar o pneu no aro da roda [6] e [4].

A banda de rodagem é a principal responsável pela resistência ao rolamento, conforme a Figura 2, por isso sua composição é de extrema importância para a definição das características finais dos pneus. A banda de rodagem e os demais componentes de borracha do pneu são constituídos por polímeros, cargas reforçantes, sistemas protetivos e cargas vulcanizantes. Cada um destes itens tem participação nas propriedades dos pneus, resistência ao rolamento, frenagem, durabilidade, etc. Os componentes adotados na composição do pneu e a proporções de cada um são determinantes no resultado final desejado [1].

Do ponto de vista de propriedades, a borracha sintética se assemelha a natural, porém com características inferiores em algumas aplicações, como em pneus automotivos, nos quais tem-se em média cerca de $14 \%$ de borracha natural e $27 \%$ de borracha sintética. É adicionado matriz da borrcacha cargas com negro de fumo, óleos que ajudam no processamento, cargas protetivas e reforçantes além de aceleradores, retardantes e outros componentes químicos. A borracha natural possui propriedades interessantes para aplicações em pneus, tanto que as borrachas sintéticas não conseguem substituí-la por completo, dentre estas propriedades destaca-se sua resisliência, elasticidade, resistência a abrasão. A borracha natural é produzida a partir de plantas, enquanto a borracha sintética é produzida dos derivados do petróleo, por esta razão costuma ser mais cara que a natural, estando suscetível a volatilidade de preços do petróleo [1] e [9]. 
Figura 2: Distribuição da resistência ao rolamento pelos componentes do pneu. Adaptada [4].

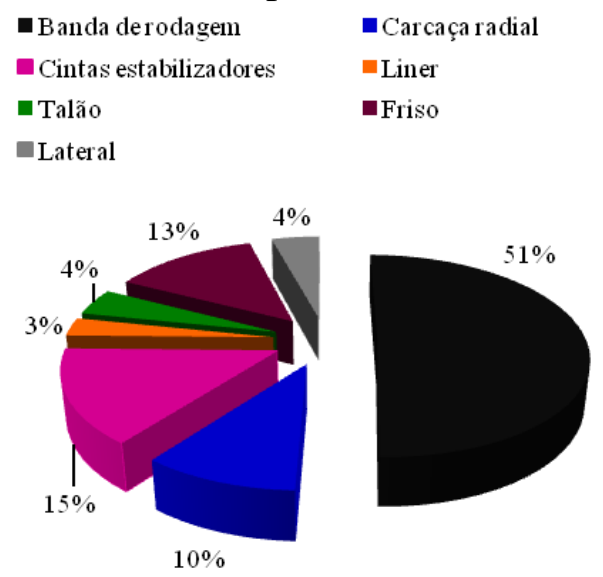

Nos materiais viscoelásticos como a borracha algumas propriedades dependem da temperatura e frequência de excitação, como as deformações cíclicas provocam aquecimento elevando a temperatura da borracha, as propriedades dos pneus sofrem alterações durante o uso [6].

Os elastômeros naturalmente não possuem resistência necessária para aplicações em veículos devido às estruturas moleculares estarem emaranhadas, mas não fortemente ligadas, por isso quando são deformadas, as cadeias poliméricas deslizam entre si e não retornam à sua forma original quando a carga é retirada. Para promover o aumento de resistência é realizado o processo de vulcanização.

A vulcanização é um processo de formações de ligações cruzadas entre macromoleculas de polímeros por meio de pontes de enxofre. A Figura 3 apresenta a distinção de ligações em borrachas vulcanizadas e não vulcanizadas. O processo de vulcanização submete o pneu cru, com as cargas vulcanizantes a temperaturas elevada, em torno de $180{ }^{\circ} \mathrm{C}$ à alta pressão, o tempo de exposição depende da aplicação do pneu, mas em geral são alguns minutos para pneus de veículos de passeio [1] e [6].

Figura 3: a - Estrutura polimérica de borracha não vulcanizada. $b$ - Estrutura polimérica de borracha vulcanizada. [6]

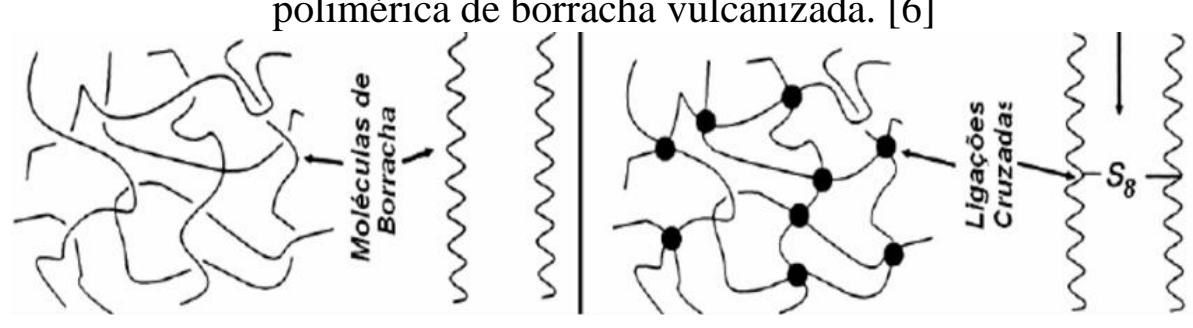

(a)

(b)

As ligaçãoes conferem ao material resultante melhores propriedades mecânicas como elevação da sua capacidade de suportar tensões aplicadas e deformações elásticas, dessa forma o material com comportamento plástico passa adquirir comportamento elástico. Além da resistência a tensões, a vulcanização também confere ao material 
maior dureza, resistência à fadiga e abrasão. A intensidade com que estas propriedades serão adquidiras depede do número de ligações formadas, densidade e distribuição das ligaçãoes, além do tempo e temperatura em que a reação é promovida. A vulcanização é economicamente viável apenas com a adição de aceleradores da reação para reduzir o tempo necessário para sua conclusão [10] e [11].

As cargas reforçantes são componentes sólidos geralmente em grande quantidade adicionada a borracha para melhorar suas propriedades mecânica. As cargas reforçantes são de grande importância para o desempenho dos pneus, as mais utilizadas são o Negro de fumo e a Sílica. O Negro de fumo aumenta o aquecimento interno, a dureza, a aderência em condições de pista molhada, porém eleva também a resistência ao rolamento. A sílica por sua vez proporciona redução da resistência ao rolamento, eleva a resistência ao corte, porém reduz a resistência ao desgaste [6].

Atualmente encontrar a melhor relação de proporção das cargas reforçantes implica em um melhor desenvolvimento de pneus para reduzir a resistência ao rolamento ao passo que se mantém as características de desempenho, principalmente em frenagem e durabilidade [1] e [6].

\subsection{Uso da Sílica nos pneus automotivos}

Existem varias formas de melhorar as propriedades dos pneus automotivos, mas com relação à resistência ao rolamento destaca-se a composição da borracha utilizada como matéria prima para produção do pneu.

Porém projetar um pneu é um desafio, pois é preciso equilibrar uma série de propriedades como resistência ao rolamento, segurança, conforto, durabilidade, etc. É observado que estas propriedades geralmente são concorrentes, quando se melhora uma as outras são penalizadas, de forma que o equilíbrio de todas elas deve ser alcançado de acordo com a aplicação de projeto [1] e [6].

O comprometimento com a segurança é uma das limitações para redução da resistência ao rolamento, pois impacta diretamente sobre a distância de parada. A durabilidade também deve ser preservada, pois a sua redução aumenta os custos de manutenção do veículo e também o número de pneus inservíveis uma vez que sua vida útil é reduzida. Além disso, o comportamento do pneu na dinâmica veicular também tem fundamental importância na seleção de um pneu em um projeto veicular [1] e [12].

O conceito de pneus de baixa resistência ao rolamento surgiu inicialmente com a ideia de reduzir as perdas de energia devido à histerese no funcionamento do pneu, que resultaria na redução de consumo de combustível, preservando as características de desempenho que estes precisam ter para aplicação em automóveis. Esta ideia de pneu também ganhou o nome popular de "Pneu verde" por reduzir o consumo de combustível fóssil. Os pneus de baixa resistência ao rolamento foram incialmente desenvolvidos pela empresa Pirelli em 1983 com a inserção de dióxido de silício $\left(\mathrm{SiO}_{2}\right)$ na composição da borracha e desde então foram melhorados e utilizados por outras empresas [1]. 
O potencial da sílica como carga reforçante na borracha foi percebido inicialmente em materiais esportivos, que apresentaram mudanças positivas nas suas propriedades com adição de sílica. Depois disso algumas empresas começaram a inserir a sílica na composição dos pneus como carga reforçante nos pneus auxiliando na redução da resistência ao rolamento e promovendo redução no consumo de combustível. Tais pneus são chamados de pneus de baixa resistência ao rolamento.

A economia de combustível com estes pneus não é consenso entre fabricante, alguns afirmam que a economia pode chegar a $4 \%$, outros defendem que ao consumo pode cair bem mais, em torno de 7\%, mas o seu uso é comprovadamente benéfico para o consumo de combustível veicular [1] e [5].

A sílica proporciona comportamentos diferentes de histerese de acordo com a frequência de excitação da matéria, como a região de frequência relacionada à resistência ao rolamento é diferente da região de frequência na frenagem, é possível com a sua adição aliar as duas propriedades, baixa resistência ao rolamento e desempenho de frenagem. Como pode ser observada na Figura $4 \mathrm{em}$ baixas frequências a histerese na borracha que contem sílica é menor (região de abrangência da resistência ao rolamento), enquanto que para altas frequências (região de frenagem) a histerese é elevada no mesmo composto [1].

Figura 4: Distribuição da resistência ao rolamento pelos componentes do pneu. Adaptado [1].

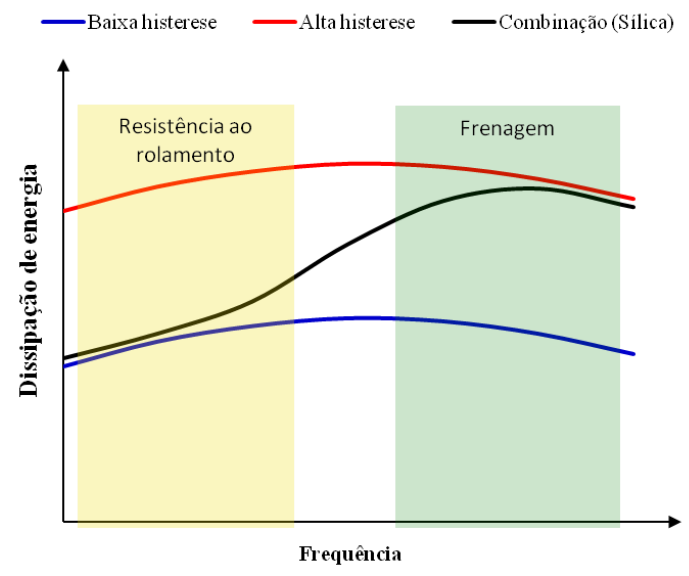

Porém não basta adicionar a sílica como matéria prima na fabricação dos pneus, é necessário utilizar borrachas com ponto de transição vítrea que seja adequado de forma que a histerese seja menor nas temperaturas de operação desejada. Além disso, outros componentes da família dos silanos são utilizados para promover as reações entre a sílica e as moléculas poliméricas [1].

O problema relacionado ao uso da sílica diz respeito ao custo à produção, que exige grande quantidade de energia. Geralmente os pneus mais eficientes, são mais caros, tornando a sua aquisição menos atrativa. Contudo atualmente existem incentivos por parte do Governo Brasileiro, que segue uma tendência mundial, para elevar a eficiência energética da frota automotiva com uma redução de consumo de combustível, tornando o uso de tais pneus mais presente nos veículos atuais. 
A sílica comum adicionada aos pneus é proveniente da areia, contudo sua fabricação exige o uso elevado e energia tornando o procedimento caro, que é repassado ao produto final. Uma alternativa desenvolvida para tornar a inserção da sílica nos pneus mais barato é a utilização das cinzas de casca de arroz, que além de requerer pouca energia para sua produção ainda contribui com a redução de resíduos que seriam desacertados em aterros. Essa aplicação foi desenvolvida em 2015 pela Goodyear [13].

Segundo alguns estudos a redução da resistência ao rolamento em torno de $10 \%$ propicia economia de combustível entre 1 e $2 \%$. A sílica comum utilizada pode reduzir a resistência ao rolamento até $20 \%$. Porém outro tipo de sílica, chamada de alto desempenho tem maior capacidade de redução, que fornece maior benefício de economia de combustível. Porém novamente o problema recai sobre o custo de fabricação [1].

\section{DISCUSSÃO}

A resistência ao rolamento é uma força dissipativa de energia que reduz a eficiência energética dos veículos automotivos por conta da histerese da borracha dos pneus. Como a composição da borracha é responsável pelas características finais dos pneus, como a resistência ao rolamento, durabilidade, aderência, entre outros é possível por meio da combinação de materiais e compostos melhorar as propriedades do pneu como a resistência ao rolamento reduzindo o consumo de combustível.

O processo de vulcanização da borracha foi essencial para aplicação dos pneus em veículos automotivos, sendo um importante passo na história da produção de veículos. A vulcanização é um processo complexo no qual o controle de cada variável influencia o resultado final do pneu. Portanto é de grande importância que o projeto e execução de um pneu sejam bem executados para atender as necessidades técnicas.

O uso da sílica e o desenvolvimento dos pneus de baixa resistência ao rolamento representam um avanço tecnológico importante na atualidade, pois com estes pneus os veículos consomem menos combustível, em um momento em que o mundo está necessitando de soluções para suprir a elevada demanda de energia mundial e mitigar os efeitos da poluição, tal avanço é grande relevância.

Com relação ao percentual de economia de combustível obtida com uso de pneus de baixa resistência ao rolamento não existe consenso por uma série de razões que envolvem fatores construtivos do pneu, composição e processos de fabricação e fatores externos como a interação do pneu com os demais componentes do veiculo e pista.

No que diz respeito ao pneu em si, a redução de consumo não é uma função simples com a adição de sílica, o resultado final é influenciado pelo tipo de sílica, as cargas reforçantes, vulcanizantes, pela proporção de cada componente, incluindo a parte estrutural, a execução do processo de vulcanização, temperaturas e tempo de exposição, os acelerantes e retardantes que serão utilizados, portanto o controle de cada variável é necessário para alcançar um objetivo. Além destes aspectos, ainda existe a influência do tipo da carcaça, perfil do pneu, desenho da banda de rodagem, entre outros aspectos que fazem a diferença entre pneus. 
A escolha de um pneu para compor um veículo passa por uma série de testes de diferentes áreas do projeto veicular como consumo, desempenho, frenagem, dirigibilidade, desgaste, entre outros. Escolher um pneu para um veículo é um trabalho conjunto, como o pneu é um elemento que influência em várias áreas do projeto veicular, a sua escolha envolve uma série de critérios a serem atendidos.

Por fim destaca-se que é importante a continuidade de estudos sobre o uso da sílica nos pneus automotivos para reduzir os custos de fabricação, por exemplo, a produção de sílica a partir do reaproveitamento de resíduos, como a casca do arroz que foi citado pode tornar o seu uso mais barato favorecendo a utilização cada vez maior destes pneus nos veículos automotivos, tal medida contribui com a redução de consumo de combustível de veículos automotivos. Assim como as pesquisas de sílicas de alto desempenho também são importantes para melhorar ainda mais a eficiência dos pneus.

\section{CONCLUSÕES}

Este artigo apresentou uma revisão da literatura sobre uso da sílica na composição da borracha de pneus automotivos para redução de consumo de combustível. Com esta pesquisa conclui-se que:

1. A resistência ao rolamento é uma força dissipativa, que eleva o consumo de combustível e que depende fortemente da composição da borracha e dos processos de fabricação do pneu;

2. O projeto de um pneu é um desafio por requerer o atendimento de diferentes propriedades simultaneamente e envolve um trabalho conjunto dentro de uma empresa automotiva e indústria de pneus;

3. O uso da sílica (dioóxido de silício) como carga reforçante dos pneus automotivos é um avanço relativamente recente importante para a indústria automotiva atualmente, visto que isso permitiu reduzir o consumo de combustível dos veículos por meio da redução da resistência ao rolamento dos pneus, sem perder as demais propriedades que são importantes em um projeto automotivo.

4. As pesquisas em torno do uso da sílica devem continuar para baratear sua aplicação na indústria automotiva favorecendo a utilização cada vez maior na frota automotiva.

Recomenda-se para trabalhos futuros estudos experimentais da influência do percentual de sílica na matriz de borracha no consumo de combustível.

\section{AGRADECIMENTOS}

Os autores agradecem à Fiat Chrysler Automobiles - FCA pelo apoio financeiro e por incentivar o desenvolvimento tecnológico automotivo no Brasil por meio do PROGRAMA INOVAR FCA - UNIVERSIDADES - RESIDÊNCIA TECNOLÓGICA PARA ENGENHEIROS. 


\section{REFERÊNCIAS}

[1] BARBOSA, Tatiane Aparecida Fernandez. Pneu verde - Desafios para equilibrar conforto, segurança e baixo consumo de combustível. São Caetano do Sul: Monografia de Especialização em Engenharia Automotiva da Escola de Engenharia de Mauá, 2013.

[2] FENDER NETO, Jorge. Estudo da influência do escalonamento de marchas no consumo de combustível de um ônibus urbano. Campinas: Dissertação de Mestrado em Engenharia Automobilística da Universidade Estadual de Campinas, 2010.

[3] WEIHERMANN, Henrique Weber. Estudo sobre aplicação de transmissão continuamente variável para veículos de pequeno porte. Joinville: Trabalho de conclusão de curso em Engenharia Automotiva da Universidade Federal de Santa Catarina, 2015.

[4] GALI, Marcos Rodolfo. Modelo analítico de resistência ao rolamento de pneus de carga. Campinas: Dissertação de mestrado da Universidade Estadual de Campinas, 2015.

[5] RHODIA. Sílica de alto desempenho para pneus verdes é tema principal de palestras técnicas da Rhodia. São Paulo: Expobor e Pneu Show 2016, 2016.

[6] CARDOSO, Fernando Aleixo. Estudo do desempenho dos compostos de borracha utilizados na fabricação da banda de rodagem dos pneus automotivos em função dos pavimentos das rodovias. São Paulo: Dissertação de mestrado em Engenharia Mecânica da Universidade de São Paulo, 2010.

[7] GILLESPIE, Thomas D. Fundamentals of vehicle dynamics. 1 ed. United States of America: SAE International, 1991.

[8] VIDAL, Marlos Ney. Economia de combustível vai muito além da evolução do motor. Site Autos Segredo. Disponível em <http://www.autossegredos.com.br/mercado/materiasespe ciais/economia-de-combustivel-vai-muito-alem-da-evolucao-do-motor/ $>$ acesso em 22/03/2017 às 10:23, 2017.

[9] LAGARINHOS, C. A. F. Reciclagem de pneus: análise do impaco da legislação ambiental através da logística reversa. Tese de doutorado - Escola Politécnica da Universidade de São Paulo: São Paulo, 2011.

[10] ARAVANIS, A. E. Efeito do sistema de reticulaçaõ nas propriedades de compostos de borracha natural para peças de engenharia do setor automotivo. Universidade Federal de Porto Alegre, 2006.

[11] BRAUM, M. V. Melhoria da interação polímero-carga através do uso de borracha de polibutadieno epoxidada. Universidade Federal do Rio Grande do Sul, Porto Alegre, 2006.

[12] OLIVEIRA, A. M. Pneus automotivos: análise crítica dos requisitos de segurança e desempenho. São Paulo: Dissertação de mestrado em Engenharia Mecânica - Universidade de São Paulo, 2005.

[13] SILVA, J. Goodyear recebe prémio ambiental. Revista dos Pneus. Disponível em <http://www.revistadospneus.com/pt/index.php/pneus/penus-produto/item/1606-goodyearrecebe-premio-ambiental> acesso em 25/05/2017 às 14:24, 2015. 